\title{
Analysis and Suggestions on the Development of Cultural Creative Products in Zhoushan
}

\author{
Jiani Yao*, Jinli Liu, Jing jing Zhan, Xinlei Zhang \\ Zhejiang Ocean University, Zhoushan, China
}

*Corresponding Author: Jiani Yao, Zhejiang Ocean University, Zhoushan, China

\begin{abstract}
In recent years, the cultural market is booming. Cultural creative products of the Palace Museum and Nanjing Museum are widely popular, such as Chaozhu headphones ${ }^{1}$ and Qinggong dolls ${ }^{2}$. Zhoushan is rich in marine culture and Buddhist culture, but there are few related cultural creative products. On the basis of full investigation, it is found that Zhoushan's cultural creative products are homogeneous and lacking in characteristics, relevant practitioners and cultural creative resources platform. What's more, the sales form is single and the competition is quite fierce. According to the problems existing in the development of Zhoushan's cultural creative products, this paper puts forward some suggestions on integrating cultural creative products with local characteristics, clustering cultural creative talents and innovating the cluster system, formulating effective marketing methods, winning support from all parties, attracting and cultivating enterprises, and cooperating with local universities. It is hoped that with the cooperation and coordination among the government, enterprises and universities, the research of development of cultural creative products in Zhoushan can get some inspirational guidance and move forward in a more promising way.
\end{abstract}

Keywords: Zhoushan; cultural creative products; current situation of development; marine culture

\section{INTRODUCTION}

In recent years, the reform of cultural system has been pushing forward. In 2011, the "Outline of the Twelfth Five Year Plan for National Economic and Social Development" requires for the first time that China build a cultural industrial base with local characteristics. In the same year, the "Decision on Deepening Some Major Issues Concerning the Great Development and Prosperity of the Cultural System Reform" listed cultural industry as the pillar industry of national economy for the first time. In 2014, in the "Interim Measures for the Management of Special Funds for the Development of Cultural Industry", the National Cultural Industry Fund was established, and for the first time, more than 800 cultural enterprises were supported. In the "State Council's Opinions on Promoting the Integration and Development of Cultural Creativity and Design Services for Related Industries", local governments are required to attach importance to the development of cultural industries. The 13th Five-Year Plan outline proposes to make the cultural industry a pillar industry of the national economy. As well as the promulgation of Article 50 of Shanghai cultural creative industries, cultural creative industries will become a new driving force to promote the transformation of China's economic growth model. Various supporting policies have been introduced continuously, the enthusiasm of all sectors of society has been thrown into the cultural industry, and the number of cultural market entities is increasing. China's cultural industry is entering the golden period of development, and the added value of cultural industry has been increasing year by year. In recent years, the cultural market is booming. Cultural creative products of the Palace Museum and Nanjing Museum are widely popular, such as Chaozhu headphones and Qinggong dolls.

Zhoushan is a city of archipelagos, which has unique resources such as mountains, seas, beaches, fishing, harbors and scenery. It has bred the distinctive culture of Zhoushan rich in historical relics, island dwellings and other material relics, as well as folk customs, religious beliefs and other intangible relics.

${ }^{1}$ Chaozhu headphones: Chaozhu is a string of beads worn on the Qing Dynasty's court clothes. It is shaped like a Rosary Bead hanging on the monk's chest. Chaozhu headphones are designed according to the image of Chaozhu.

${ }^{2}$ Qinggong dolls: The doll designed according to the characters of the royal court in Qing Dynasty. 
The unique geographical position created the brilliant Buddhism and marine culture in Zhoushan. According to the 2010 general survey of intangible cultural heritage, Zhoushan has a preliminary statistics of more than 100 intangible cultural heritage, which is distributed in Dinghai, Daishan, Putuo and Shengsi counties. At the same time, Zhoushan's intangible cultural heritage is rich in content, which can be divided into: folk art, agricultural products processing technology, traditional wooden boat manufacturing technology, fishing gear and fishing rope manufacturing technology, sea salt and seafood manufacturing technology, wine and sauce making technology, agricultural and livestock products processing technology, folk beliefs, Guanyin Buddhist beliefs, fish legends, historical legends and so on. Among them, there are five national-level items. They are Zhoushan gongs and drums, Guanyin legend, Zhoushan fishermen's chant, traditional wooden boat manufacturing skills, fishermen's Xie Yang Festival ${ }^{1}$. There are 29 items listed as provincial level. There are 62 items on the list of intangible cultural heritage in Zhoushan.

Although Zhoushan has rich Buddhist and marine cultural resources, there are very few related cultural derivatives, and the current situation of its cultural creative products is worrying. In view of this phenomenon, we have carried out a survey and analysis of the development of cultural creative products in Zhoushan. During the summer vacation of 2018, Qianyu Group of Zhejiang Ocean University launched social research in Dinghai Ancient City, Nandong, Nansha and Putuo of Zhoushan. Through questionnaires, interviews and so on, team members had a thorough understanding of the current development of cultural creative products in Zhoushan, analyzed the existing problems in the development of cultural creative products in Zhoushan, and came up with suggestions for the development of cultural creative products in Zhoushan so as to contribute to the development of blue economy and the construction of beautiful islands.

\section{METHODS}

\subsection{Participants}

The participants of this survey are tourists in Zhoushan, cultural creative shopkeepers, local people and craftsmen. The research participants cover a wide range and a large number. The main participants of the questionnaire survey are tourists in Zhoushan. The main participants of the interview are cultural creative shopkeepers and craftsmen, as well as a small number of tourists and local people in Zhoushan.

\subsection{Questionnaire}

Teams distributed questionnaires in scenic spots with relatively concentrated population, such as Dinghai, Putuo and Nansha, mainly to investigate the factors affecting the development of Zhoushan cultural creativity from the perspective of tourists and local people. Through the data of the questionnaire, this paper analyzed the problems existing in Zhoushan cultural creativity and some solutions.

\subsection{Interview}

Team members conducted in-depth interviews with the owners of cultural creative stores in Dinghai, Putuo, Zhu Jiajian and some other places to understand their views on Zhoushan cultural creativity from the perspective of sellers, as well as some existing difficulties and their expectations and suggestions for Zhoushan cultural creativity, so as to find out the root causes of problems and solutions to cultural creativity.

Qianyu Group investigated Dinghai, Putuo, Nansha and other places one after another. In the process of investigation, the team members saw a lot of beautiful crafts, but what was unexpected behind these cultural creative products was the poor sales.

In order to understand the factors affecting the development of cultural creative products of Zhoushan, Qianyu Group started from the market and investigated the real market through questionnaire. Team members randomly distributed questionnaires to passers-by in non-scenic areas such as Dinghai City and scenic areas such as Putuo and Zhujiajian, and collected 200 valid questionnaires. Team members exported questionnaire data and conducted data analysis.

\footnotetext{
${ }^{3}$ Xie Yang Festival: The festival celebrating the fishing season and giving thanks to the generous ocean. 


\section{RESULTS AND DISCUSSION}

\subsection{Results}

\subsubsection{Results of Questionnaires}

Among the 200 valid questionnaires collected, $45.29 \%$ were answered by males and $54.71 \%$ were by females, aged between 18 and 60. It shows that the age structure and sex ratio of the questionnaire data are reasonable.

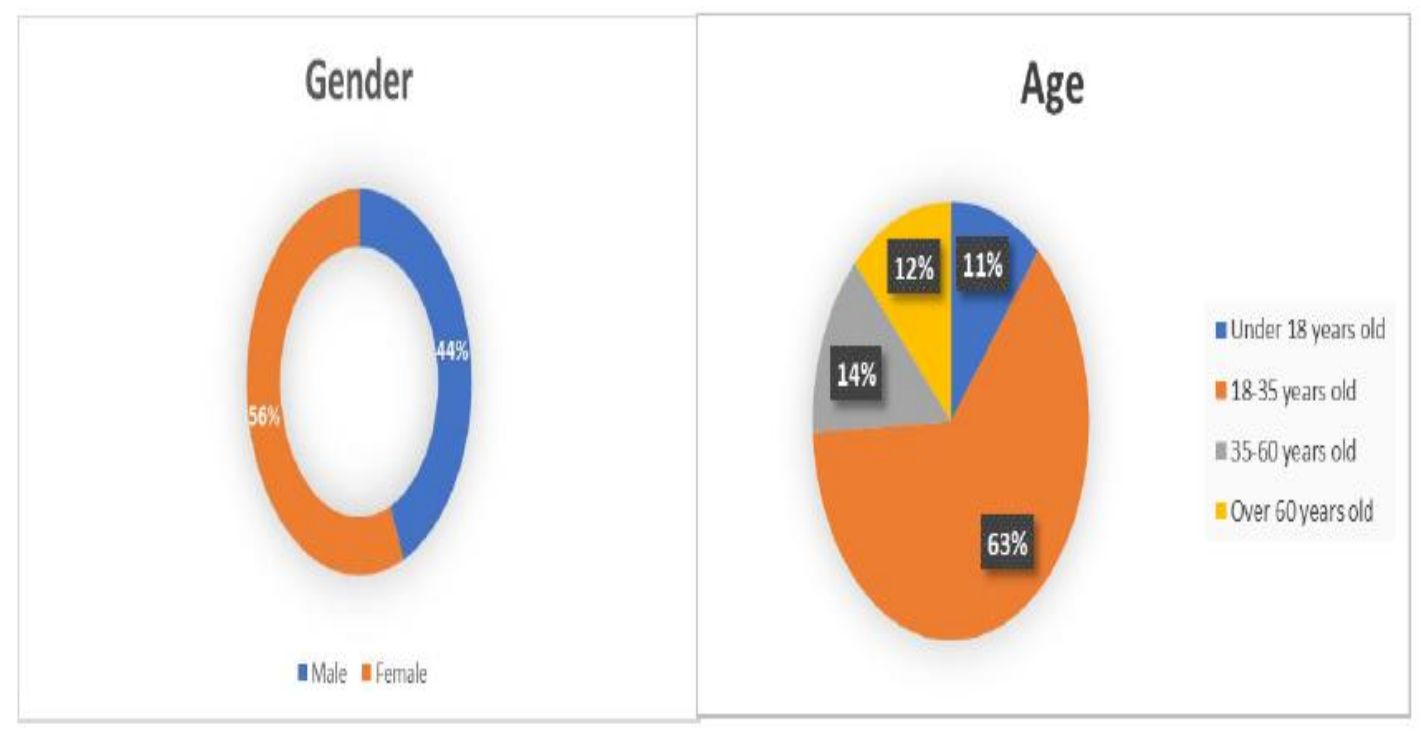

When asked from what channels to learn about cultural creativity, $58.82 \%$ of passers-by said they knew cultural creativity through the Internet and other news reports, while $31.37 \%$ of passers-by said they did not pay attention to cultural creativity. It shows that the mass media has broadened people's awareness of society and played an important role in people's understanding of cultural creativity, but the public's attention to cultural creativity of Zhoushan needs to be enhanced.

In the survey, only $37 \%$ of passers-by were satisfied with the development of Zhoushan's cultural creative industry, while $51 \%$ of passers-by said they did not know about Zhoushan's cultural creative industry, which shows that most people are still not optimistic about Zhoushan's cultural creative industry, or even do not understand it. Although most of the current stores have online and offline sales, marketing a wide range, but after leaving the scenic area, sales are generally not high. In our survey of a shop named Alawoli, the monthly sales of its online stores are basically 0 , indicating that once leaving Zhoushan its products are not popular.

\section{Your attitude towards the development of cultural creative industry in Zhoushan}

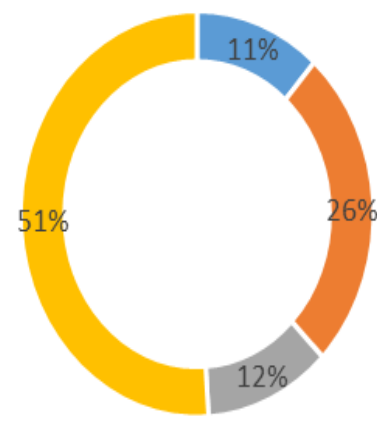

घerysatisfied $\quad$ Satisfied $\backsim$ Dissatisfied $\llbracket$ Do not understand 
When questioned about the pricing range of the most acceptable cultural creative products, $36.73 \%$ of the passers-by said they accepted the products of 5-30 yuan, and the higher the price, the fewer people accepted them. If the price of cultural creative products exceeded 100 yuan, only $8.16 \%$ of the passers-by said they could accept them. It shows that price also has some influence on people's desire to buy, but as long as the price is reasonable and within the acceptable range of people, the higher the performance-price ratio of products, the easier it will be for people to buy.

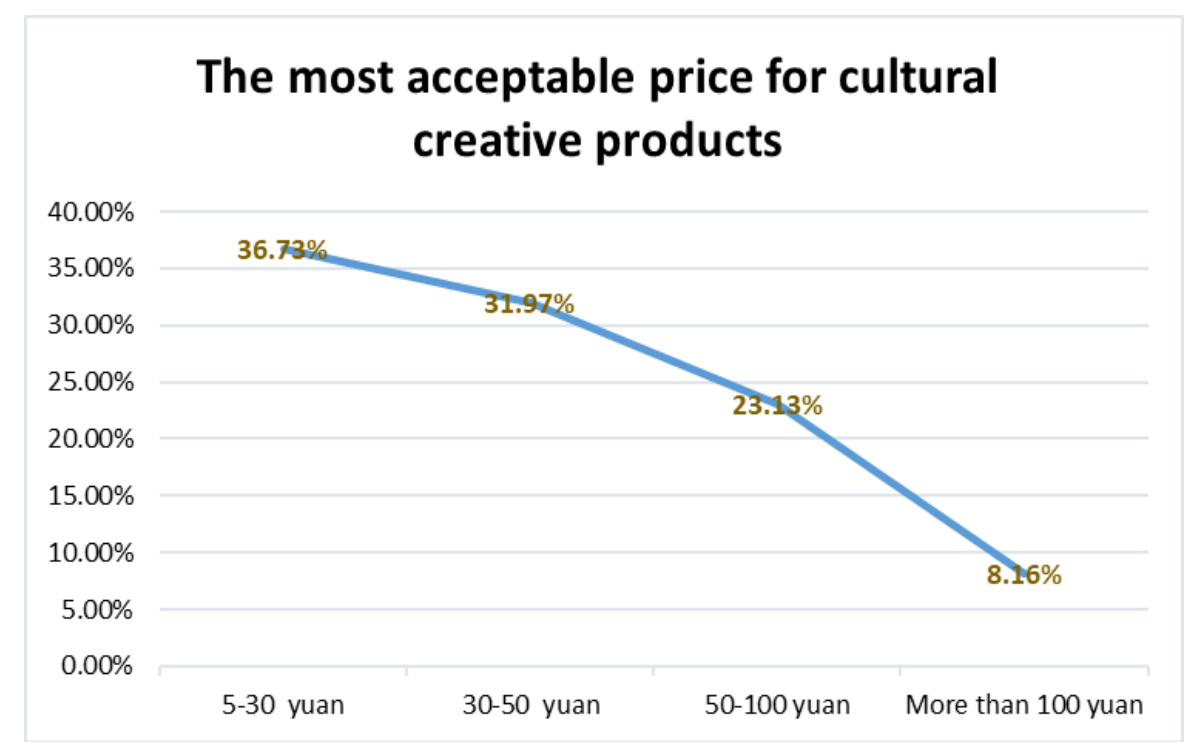

When asked whether product packaging affects shopping desire, about $70 \%$ of passers-by said it was affected by product packaging. This also shows that people tend to buy well-packaged products. People buy cultural creative products for various purposes, some for souvenir, some for the gift of relatives and friends, some for collection hobbies, or their own use, etc. In the team survey, $80.39 \%$ of the people are for the souvenir and gift of relatives and friends. It shows that people need to buy some special products in the process of traveling.

Throughout the research process, the team found that people buy cultural creative products mainly because they have local characteristics, while Zhoushan's rich marine culture and Buddhist culture make people want to buy products with marine characteristics and Buddhist cultural characteristics. Among them, practicability, innovation and aesthetics are the three most important factors that can affect people's purchase of cultural creative products.

\section{Factors influencing the purchase of cultural creative products}

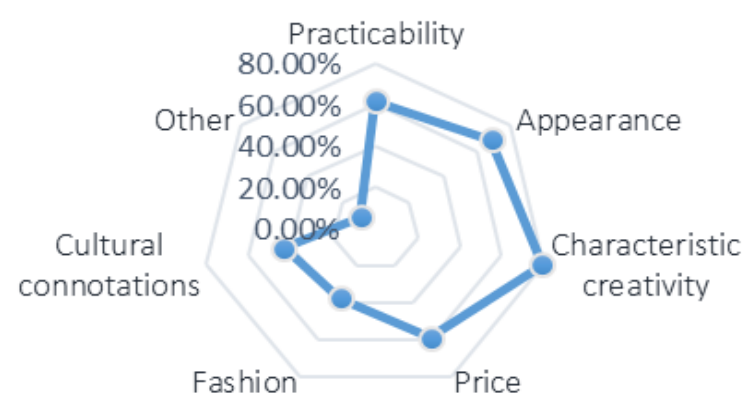

\subsubsection{Results of Interview}

On the basis of the questionnaire, we conducted interviews. The interviews mainly focused on the owners of cultural creative products shops and folk craftsmen. When interviewing the characteristic boat model shop, the "Alawoli" cultural creative product shop and the fishermen's painting studio, the 
team members saw a lot of dazzling handicraft products, but unexpectedly, behind these dazzling handicraft products is the dismal sales, especially Zhoushan characteristic fishermen's paintings. Ms. Zhou of Wangchao Fishermen's Painting Studio said, "Fishermen's Painting is gradually declining due to the lack of relevant practitioners." Moreover, the team members also learned from some store managers in Putuo that the current situation of Zhoushan's cultural creative products is characterized by single sales form, fierce competition in physical stores and poor sales. A shop owner in Nansha Square pointed out that "the threshold of cultural creative industry is not high, and the quality of employees is uneven. It is difficult to combine cultural creative industry with advanced technology". The famous scenic spot of Zhoushan is Mount Putuo, but the products in the scenic spot of Mount Putuo suffer from severe homogeneity and lack characteristics. For example, in Mount Putuo scenic area, almost every shop's products are conch, shell bell, Buddha bead bracelet, etc. As there are no novel products, and the craftsmanship is not high, the quality is worrying, it is easy to cause aesthetic fatigue and less desire of buying. Without any brand names, Zhoushan's local cultural creative enterprises are on the small-scale, it is easy to copy them. More importantly, it lacks a powerful platform supported by the government for propaganda and promotion, which makes it difficult for the cultural creative industry to develop in Zhoushan. In a word, at present, Zhoushan's cultural creative industry is facing enormous challenges and need to be improved urgently.

\subsection{Results Analysis}

On the basis of data analysis of the questionnaire and interviews of some shopkeepers and tourists, we find that cultural creativity in Zhoushan has a lot of problems. In this regard, we make the following analysis to tackle specific problems:

1) Severe homogeneity and lacking in characteristics of cultural creative products. In the famous scenic spots of Zhoushan, such as Mount Putuo scenic area and Zhujiajian Sand-Sculpture Park, it is not difficult to find that most of the cultural creative products, sold in the shops there, are shell bells, Buddha bead bracelet and other homogeneous products, which obtained materials from local sources. These result in similar cultural creative products in different scenic areas and the same cultural creative products in different shops in the same scenic area. It brings visual fatigue to consumers. The products are flat and have no innovative features, which reduces consumers' desire to buy. At the same time, such products have no cultural connotations. By contrast, the cultural creative products of the Palace Museum have rich connotations and are sought after by people. This also makes people lose interest in Zhoushan's cultural creative products.

2) Sales form is single and hypostatic store competition is intense. At present, some cultural creative stores in Zhoushan are hypostatic stores, and only a few owners own online stores. Hypostatic stores are mainly located in scenic spots or urban areas where there is a large flow of people. However, identical products, single type, similar prices and neighboring location jointly form a market with intense competitiveness. In addition, there are a small number of small vendors selling this kind of products in the scenic area, and the price is more favorable than that of the store products, which also makes the competitiveness of the cultural creative products in the scenic area increased.

Moreover, the shops of Zhoushan's special products in Taobao and other popular Apps are not as popular as those of the Forbidden City. Without the scenic spots, it is hard to imagine that there are such cultural creative products. In addition, there is no strong propaganda, so few people are interested in them, which makes the sales of these products very poor and almost nobody buys them.

3) It is difficult to combine cultural creative industry with advanced technology because of the low threshold of employment, lack of relevant practitioners and uneven quality of practitioners. In the process of investigation, we inquired about some relevant information from the shopkeepers. Ms. Zhou, who works in a fisherman-painting studio called Guan Chao, said that there were few relevant practitioners and the situation was not optimistic. Specifically, there are few people who master traditional skills. Furthermore, young people do not have time and energy to learn fisherman painting, since this kind of skill cannot be achieved overnight. As the source of creativity, people are obviously the most important capital of cultural enterprises (Li, 2019). As Ms. Zhou said, she had been learning fisherman painting for around 30 years before her success. Moreover, the manager of cultural creative stores in Putuo related the threshold was not high and it was easy to egage in this business as long as the owners wholesale some shellfish decorations. Since not all practitioners have a solid professional knowledge and skills, it is difficult to make the industry combine with advanced technology. 
4) Zhoushan cultural creative industry is weak, and there is a serious gap in cultural creative resource platform. In the field investigation of Putuo mountain, Zhu Jiajian, Da Qing mountain and other famous tourist attractions in Zhoushan, we found that the shops are mainly pedlars without business licenses. The cultural creative products sold in these shops are nothing new and have little to do with the culture of Putuo Buddha and the culture of fishermen in Zhoushan. In addition, according to tourists, our team members also found that they were not interested in these products and had no desire to buy them. What's more, interviewees said that there were two most important points to check whether the cultural creative products can circulate in the market. One is containing unique local culture, the other is creativity. In an interview with Ye Jianhua, a Deputy Director of the Tourism and Religious Affairs Office of Putuo Management Committee, we further learned that, the market of cultural creativity lacks the support of the government to effectively integrate Buddhism and Marine cultural resources. Mr. Ye also figured the government was willing to invest to build a public platform integrating Buddhism and Marine cultural resources.

\subsection{Suggestions}

Based on the data analysis of the questionnaire and interviews with some shopkeepers and tourists, we put forward the following suggestions on the development of Zhoushan cultural creativity:

- Cultural creative products need to combine local characteristics to attract tourists. Zhoushan is a city of islands, and Zhoushan Putuo is well-known far and wide. The cultural creative product designers can deeply process Zhoushan's unique marine culture, Buddhist culture and other resources, create Zhoushan's unique cultural creative products, and commercialize creativity. The original art is rooted in production and manufacturing, so that art and cultural creativity can be combined, and then the value of cultural creative products can be enhanced. Cultural creativity is the process of exploring the pluralistic value of cultural resources with cultural concepts and injecting fresh cultural elements (concepts, emotions and tastes) into products and services to make them become a cultural symbol Li, 2019. Secondly, we can create a brand of cultural creative products. In the process of making products, the designers need not only quantity, but also the cultural connotation of the products. Cultural creative products cannot be separated from profound cultural connotations (Wang, 2019). For example, Zhoushan has more than 1000 Buddhist cultural landscapes, natural landscapes of mountains and seas, and fishery custom landscapes of islands, mainly distributed on 23 islands. Each island has different attributes and characteristics, such as martial arts culturein Taohua Island, sea fishing paradise in Baisha Island, miracle stone in Huanglong Island, etc. We can design an exclusive brand for each island to attract customers.

- Gathering high-caliber cultural creative talents and innovating a more competitive system of cultural creative talent cluster. Talents, as the core element of cultural industry development, play an important role in driving urban innovation (Yang and Chang, 2019). As the first state-level marine new area, Zhoushan's economic development has been witnessed by the public in recent years. Because Zhoushan is an island, its living cost is high, so if we want to attractcultural creative talents in large number, we need to find a new way. For example, we should establish and improve the talent training system, strengthen the propaganda of Zhoushan's local characteristics, and clarify its development prospects. Secondly, it will provide convenience for cultural creative talents and further optimize the innovation environment. Furthermore, the government can build a cultural creative garden or a cultural creative fair to gather the existing old craftsmen in Zhoushan and bring their talents into full play.

- Develop effective marketing methods. The sales channels of cultural creative products are online sales and offline sales. Shopkeepers need to formulate different sales strategies according to different sales channels. For example, in the offline sales of physical stores, shopkeepers can use cooperation with Mount Putuo, Zhu Jiajiajian, Nansha and other scenic spots, relying on the popularity of scenic spots to create their own brand. It can also cooperate with hotels around scenic spots to put products on display in hotels, or use cultural festivals to carry out special sales, that is, to design relevant cultural creative products that conform to the characteristics of Putuo Mountain Festival, and to sell specific creative products at specific cultural festivals. 
- Enlist the support of all parties, especially the government's vigorous guidance. At present, most of the enterprises in Zhoushan developing cultural creative products are small micro-creative enterprises (SME). In order to win support from all parties, the government should strengthen its guidance. The government can provide support from the following perspectives: (1)setting up a special management institution to support SMEs; (2) opening up channels and establishing a reserve system for SMEs' development through multi-financing; (3) training talents and renewing ideas for SMEs' development; (4) strengthening information and technical guidance for SMEs; (5) To provide a good market environment for the development of SMEs, we should deepen reform and develop market economy; (6) Establishing and perfecting the legal system to form a good macro-environment conducive to the development of small and medium-sized enterprises; (7) the government can organize cultural creative activities regularly, such as cultural creative fairs, to strengthen the exchanges between cultural creative designers and inject fresh vitality into cultural creativity.

- Attracting and nurturing enterprises and focusing on the cultural creative teams with state-owned strength. Attract and cultivate enterprises, and focus on the state-owned strength of the cultural creative team. Making use of the advantages and experiences of large enterprises in management, technology and industrial upgrading, perfecting the interactive development mechanism of small micro cultural creative enterprises, giving full play to the driving role, and promoting the development of small micro cultural creative enterprises. For example, they can learn from the success of the Palace Museum and Nanjing Museum. In this process, small micro-creative enterprises also need to rely on their own conditions and seize the opportunity to transform or upgrade.

- Cooperate with local universities to inject fresh blood into cultural creativity. Students can dig deep into the essence of local history and culture (Zhang, 2019).The local universities in Zhoushan include Zhejiang Ocean University and Zhoushan Campus of Zhejiang University. Zhejiang Ocean University hosted Zhejiang Marine Culture Creative Design Competition. Every year, there are many excellent creative design works of marine culture born here. These works all publicize the vitality of college students' youth and creativity, which also provides continuous creative and design inspiration for Zhoushan creative products. Cooperation with universities and incorporating these works into Zhoushan's cultural creative undertakings can provide opportunities for the development of Zhoushan's cultural creative products.

\section{CONClusion}

In conclusion, the unique geographical position has created a brilliant marine culture in Zhoushan. There are countless islands like Zhoushan in China. The cultural creativity of marine culture has not been tapped into a long time. How to develop marine culture, appreciate it and enhance its economic value is the general trend. According to the actual situation of Zhoushan, the Qianyu Group put forward practical suggestions for Zhoushan cultural creativity, which can inherit and carry forward marine culture, raise people's awareness of marine culture and promote island economic development, in order to revitalize the island and save "blue cultural capital".

\section{REFERENCES}

[1] Ieva Moore, Cultural and Creative Industries concept - a historical perspective, Procedia - Social and Behavioral Sciences, Vol.110, Pp 738-746, (2014).

[2] Li Qiong, Research on the Development Strategy of Heilongjiang Cultural and Creative Industries, Journal of Suihua University, Vol.39.No.6, Pp 24-26, (2019).

[3] Li Xijian, Activating the Tourism Aesthetic Effectiveness of Non-material Cultural Heritage Resources with Cultural Creativity, Tourism Tribune, Vol.35.No.5, Pp 9-11, (2019).

[4] Wang Chuanhe, Regional Characteristics Achieve the Charm of Creative Products, Guizhou Daily, (2019).

[5] Yang Yadong and Chang Tiankai, Research on the Effective Promotion of Urban Innovation-driven Development by Cultural Industry_ _ A Case Study of Shijiazhuang City, Hebei Province, Journal of Heilongjiang Vocational Institute of Ecological Engineering, Vol.32.No.3, Pp 49-54, (2019).

[6] Zhang Jingjing, Research on Cultural Creative Product Design in Universities, Art Education Research, (8), P64-65, (2019). 


\section{AUTHORS' BIOGRAPHY}

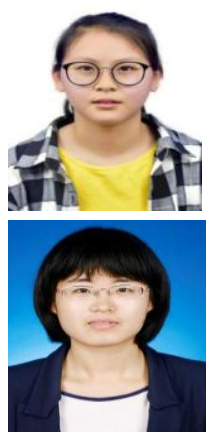

Jiani Yao, China, was born in Zhejiang, China in 1998. She is currently a college student in Zhejiang Ocean University, Zhoushan, China. Her research interests include culture.

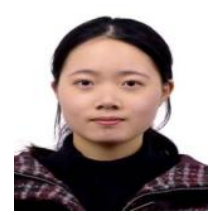

Jingjing Zhan, China, was born in Zhejiang, China in 1998. She is currently a college student in Zhejiang Ocean University, Zhoushan, China. Her research interests include culture.

Jinli Liu, China, was born in Shandong, China in 1984. She is currently a lecturer in the Foreign Language School of Zhejiang Ocean University, Zhoushan, China. Her academic interests include business culture, English literature, and cultural studies in general.

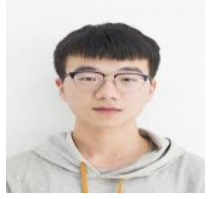

Xinlei Zhang, China, was born in Zhejiang, China in 1998. He is currently a college student in Zhejiang Ocean University, Zhoushan, China. His research interests include physics and culture.

Citation: Jiani Yao, Jinli Liu, et.al. "Analysis and Suggestions on the Development of Cultural Creative Products in Zhoushan". International Journal of Humanities Social Sciences and Education (IJHSSE), vol. 6, no.7, 2019, pp. 14-21. doi: http://dx.doi.org/ 10.20431/2349-0381.0607003.

Copyright: (c) 2019 Authors. This is an open-access article distributed under the terms of the Creative Commons Attribution License, which permits unrestricted use, distribution, and reproduction in any medium, provided the original author and source are credited. 